\title{
Respon Pertumbuhan Tanaman Junggul (Crassocephalum crepidioides) terhadap Pemberian Berbagai Jenis Pupuk Kandang dan Kosentrasi Boron
}

\author{
Saniman ${ }^{1 *}$, Mahayu Woro Lestari ${ }^{1}$, Sugiarto' dan Siti Asmaniyah ${ }^{1}$ \\ ${ }_{1}^{1}$ Departemen Agroteknologi, Fakultas Pertanian, Universitas Islam Malang, \\ Jalan MT. Haryono, No. 193, Malang 65144, Jawa Timur, Indonesia \\ Email korespondensi: saniman220696@gmail.com
}

\begin{abstract}
Abstrak
Salah satu tumbuhan berkhasiat obat yang di kenal masyarakat adalah tumbuhan junggul (Crassocephalum crepidioides). Tanaman ini merupakan tanaman semak belukar yang tumbuh liar di wilayah tropis dan sub tropis. Penelitian bertujuan untuk mengetahui interaksi antara perlakuan jenis pupuk kandang dan kosentrasi boron serta pengaruh jenis pupuk kandang dan konsentrasi boron terhadap pertumbuhan dan kualitas tanaman junggulan (Crassocephalum crepidioides). Metode yang dipakai yaitu Rancangan Acak Kelompok (RAK) faktorial. Faktor 1 adalah pupuk kandang yaitu Po = Tanpa Pupuk, P1 = Kotoran Ayam 50 gr/Polybag, P2 = Kotoran Kambing 50 gr/Polybag dan P3 = Kotoran Sapi $50 \mathrm{gr} /$ Polybaq. Dosis anjuran yang digunakan adalah 20 ton/ha. Faktor 2 adalah pemberian Boron yaitu Bo $=$ Tanpa Boron, B1 $=50 \mathrm{ppm} / \mathrm{L}, \mathrm{B} 2=100$ $\mathrm{ppm} / \mathrm{L}$ dan $\mathrm{B} 3=150 \mathrm{ppm} / \mathrm{L}$. Analisis ragam (Uji F) dengan taraf $5 \%$ dan uji lanjutan dengan Beda Nyata Jujur (BNJ) taraf $5 \%$. Hasil pemberian jenis pupuk kandang sapi (P3) berpengaruh nyata pada jumlah cabang (8,11 cabang), luas daun (1810,08 cm2), dan bobot kering berangkas tanaman $(9,57 \mathrm{~g})$ untuk pupuk kandang sapi (P3) dan $(6,27$ g) untuk pupuk kandang kambing (P3). Perlakuan pemberian Boron tidak menunjukkan perbedaan nyata pada pertumbuhan dan hasil tanaman junggulan.
\end{abstract}

Kata kunci: Crassocephalum crepidioides, Kotoran Kandang, Boron

\begin{abstract}
One of the medicinal plants known to the public is the superior plant (crassocephalum crepidioides). This plant is a shrub that grows wild in the tropics and sub-tropics. The aim of the study was to determine the interaction between the type of manure and the concentration of boron and the effect of manure and boron concentration on the growth and quality of crassocephalum crepidioides. The method used is factorial Randomized Block Design (RBD). Factor 1 is manure namely $\mathrm{Po}=$ No Fertilizer, $\mathrm{P} 1=$ Chicken Manure $50 \mathrm{gr} /$ Polybag, P2 = Goat Manure $50 \mathrm{gr} /$ Polybag and P3 = Cow Manure $50 \mathrm{gr} /$ Polybaq. The recommended dosage used is 20 tons / ha. Factor 2 is giving Boron namely Bo = No Boron, B1 $=50 \mathrm{ppm} / \mathrm{L}, \mathrm{B} 2=100 \mathrm{ppm} / \mathrm{L}$ and B3 $=150 \mathrm{ppm} / \mathrm{L}$. Analysis of variance (Test F) with a level of $5 \%$ and a follow-up test with Honest Real Difference (BNJ) level of $5 \%$. The results of the type of cow manure (P3) gave a significant effect on the number of branches ( 8.11 branches), leaf area $(1810.08 \mathrm{~cm} 2)$, and trimmed dry weight of tanman $(9.57 \mathrm{~g})$ for cow manure (P3) and ( $6.27 \mathrm{~g})$ for goat manure (P3). The treatment of giving Boron does not show a significant difference in the growth and yield of juntung plants.
\end{abstract}

Keywords: Crassocephalum crepidioides, Manure, Boron

\section{Pendahuluan}

Salah satu tumbuhan berkhasiat obat yang di kenal masyarakat adalah tumbuhan junggul (Crassocephalum crepidioides). Tanaman ini merupakan tanaman semak 
belukar yang tumbuh liar di wilayah tropis dan sub tropis. Tumbuhan ini memiliki khasiat untuk menyembuhkan luka, mengobati sakit perut dan sebagai pembersih luka (Baherta dan Napitupulu, 2010). Pertumbuhan Junggul (Crassocephalum crepidioides) akan baik pada tanah yang mengandung banyak unsur hara, baik makro maupun mikro serta kandungan air tanah yang cukup dan seimbang. Junggul umumnya sulit dijumpai pada tanah-tanah marginal. Salah satu upaya yang dapat dilakukan untuk menanggulangi hal tersebut dengan penambahan unsur hara melalui pemupukan dan penyemprotan boron.

Salah satu faktor yang menunjang tanaman untuk tumbuh dan berproduksi secara optimal adalah ketersediaan unsur hara dalam jumlah yang cukup di dalam tanah. Jika tanah tidak dapat menyediakan unsur hara yang cukup bagi tanaman, maka pemberian pupuk perlu dilakukan untuk memenuhi kekurangan tersebut. Setiap jenis unsur hara yang dibutuhkan oleh tanaman, tentunya memiliki fungsi, kelebihan dan kekurangannya masing-masing. Memberikan unsur hara pada tanaman tentunya sangat penting dijaga keseimbangan dan pengaturan kadar pemberian unsur hara tersebut, sebab jika kelebihan dalam pemberiannya akan tidak baik (Adimihardja, dkk, 2000). Boron (B) merupakan salah satu unsur hara mikro yang penting bagi tanaman. Boron berperan dalam pembentukan atau pembiakan sel terutama dalam titik tumbuh pucuk, juga dalam pertumbuhan tepung sari, bunga, dan akar. Boron mengandung unsur hara mikro essensial boron (b) yang sangat dibutuhkan bagi pertumbuhan dan perkembangan tanaman serta dapat meningkatkan hasil tanaman (Seadh, 2009). Tujuan dari penelitian ini adalah mengetahui pertumbuhan tanaman junggul yang telah diaplikasikan berbagai jenis pupuk kandang dan berbagai dosis boron.

\section{Bahan dan Metode}

Penelitian dilaksanakan di polybag pada ketinggian tempat $\pm 516 \mathrm{~m}$ dpl. Penelitian dilaksanakan pada Januari - Maret 2019. Metode penelitian menggunakan Rancangan Acak Kelompok (RAK) faktorial. Faktor 1 dengan dosis anjuran pupuk kandang 20 ton/ha. Perlakuan $\mathrm{P} 0=$ tanpa pupuk kandang, $\mathrm{P} 1=$ pupuk kandang ayam, $\mathrm{P} 2=$ pupuk kandang kambing dan P3 = pupuk kandang sapi. Faktor 2 : Konsentrasi Boron : B0 = tanpa boron, $B 1=50 \mathrm{ppm}, \mathrm{B} 2=100 \mathrm{ppm}$ dan B3 $=150 \mathrm{ppm}$. Data dianalisis menggunakan uji anova F 5\% dan di uji lanjut dengan BNJ 5\%. Analisis yang diamati jumlah cabang, luas daun, bobot segar daun kosumsi, bobot kering brangkasan, kandungan klorofil, total padatan terlarut, dan vitamin C. 


\section{Hasil dan Pembahasan}

Hasil analisis ragam (Anova) menunjukkan secara umum tidak ada interaksi antara Pemberian jenis pupuk kandang dan boron terhadap pertumbuhan tanaman. Secara terpisah perlakuan jenis pupuk kandang menunjukkan perbedaan yang nyata pada variable jumlah cabang, luas daun dan bobot kering berangkasan. Perlakuan pemberian jenis pupuk kandang dan Boron tidak menunjukkan perbedaan nyata pada bobot segar daun kosumsi, klorofil, total padatan terlarut dan vitamin $\mathrm{C}$.

Tabel 1. Rata-rata variabel pertumbuhan pada perlakuan berbagai jenis pupuk kandang

\begin{tabular}{ccccc}
\hline & \multicolumn{5}{c}{ Rata-rata Variabel Pertumbuhan } \\
\cline { 2 - 5 } Perlakuan & $\begin{array}{c}\text { Jumlah } \\
\text { Cabang }\end{array}$ & $\begin{array}{c}\text { Luas Daun } \\
\left(\mathrm{cm}^{2}\right)\end{array}$ & $\begin{array}{c}\text { Bobot } \\
\text { Segar Daun Kosumsi } \\
(\mathrm{g})\end{array}$ & $\begin{array}{c}\text { Bobot Kering } \\
\text { Berangkasan } \\
(\mathrm{g})\end{array}$ \\
\hline $\mathrm{P}_{0}$ & $3,97 \mathrm{a}$ & $1166,19 \mathrm{a}$ & 7,38 & $5,74 \mathrm{a}$ \\
$\mathrm{P}_{1}$ & $4,89 \mathrm{a}$ & $1209,11 \mathrm{a}$ & 8,40 & $5,38 \mathrm{a}$ \\
$\mathrm{P}_{2}$ & $4,83 \mathrm{a}$ & $1236,08 \mathrm{ab}$ & 8,73 & $6,27 \mathrm{a}$ \\
$\mathrm{P}_{3}$ & $8,11 \mathrm{~b}$ & $1810,08 \mathrm{~b}$ & 8,61 & $9,57 \mathrm{~b}$ \\
\hline BNJ 5\% & 2,37 & 575,15 & $\mathrm{TN}$ & 2,13 \\
\hline Keterangan: TN & : Tidak Nyata & & \\
& BNJ : Beda Nyata Jujur 5\%
\end{tabular}

Tabel 1, menunjukkan perlakuan jenis pupuk kandang menunjukkan perbedaan nyata pada jumlah cabang 8,11 cabang, luas daun $1810,08 \mathrm{~cm}^{2}$, dan bobot kering brangkasan 9,57 g. Secara keseluruhan menunjukan bahwa untuk meningkatkan pertumbuhan vegetatif junggul perlu dilakukan pemberian pupuk kandang. Peningkatan kandungan unsur hara dalam tanah dapat meningkatkan pertumbuhan dan hasil tanaman. Unsur hara yang diserap dari dalam tanah diangkut ke bagian atas tanaman dan berperan memacu proses fotosintesis. Hasil dari fotosintesis akan di translokasikan keseluruh bagian tanaman untuk memacu pertumbuhan. Hasil fotosintat dari tanaman junggul akan dipergunakan pembentukan luas dau, jumlah cabang, bobot kering brangkasan.

Pada variabel pengamatan bobot segar daun kosumsi nilai tertinggi yang dihasilkan pada perlakuan pupuk kandang kambing $\left(\mathrm{P}_{2}\right)$ yaitu 8,73 $\mathrm{g}$ tidak berbanding jauh dengan perlakuan pupuk kandang sapi $\left(\mathrm{P}_{3}\right)$ yaitu 8,61 g. Pupuk kandang merupakan pupuk majemuk yang kompleks mengandung lebih dari satu macam unsur hara tanaman (makro maupun mikro) terutama $\mathrm{N}, \mathrm{P}$, dan $\mathrm{K}$. jenis pupuk kandang sapi $\left(\mathrm{P}_{3}\right)$ berdasarkan analisis kimia jenis memiliki kandungan Nitrogen $(\mathrm{N}) \quad 0,3 \%$ (Adimihardja dkk, 2000). Kandungan $\mathrm{N}$ sangat penting bagi pertumbuhan tanaman. Pupuk kandang menggandung unsur hara yang sangat dibutuhkan tanaman yaitu 
berupa Kalium $(\mathrm{K})$ yang dapat meningkatkan pertumbuhan dan ketahanan tanaman dari kekeringan, hama dan penyakit. Selain itu pupuk kandang memiliki sifat yang alami dan tidak merusak tanah, pupuk kandang berfungsi untuk meningkatkan daya menahan air, aktivitas mikrobiologi tanah, nilai kapasitas tukar kation dan memperbaiki struktur tanah sehingga sangat penting untuk menunjang pertumbuhan tanaman junggul.

Adimihardja dkk, 2000 melaporkan bahwa pupuk kandang mempengaruhi pertumbuhan tanaman secara langsung dan tidak langsung. Pengaruh langsung pupuk kandang terhadap pertumbuhan tanaman terjadi karena pupuk kandang menjadi sumber hara makro dan mikro bagi tanaman sebagai unsur hara dalam bentuk anorganik yang siap diserap oleh tanaman dan sebagian yang lain dilepaskan secara bertahap melalui proses mineralisasi bahan organik sehingga membentuk suatu pupuk dengan pelepasan lambat yang menyediakan hara secara bertahap bagi tanaman.

Tabel 2. Rata-rata variabel kualitas tanaman pada perlakuan pupuk kandang

\begin{tabular}{cccc}
\hline & \multicolumn{3}{c}{ Rata-rata Variabel Kualitas } \\
\cline { 2 - 4 } Perlakuan & $\begin{array}{c}\text { Total Padatan } \\
\text { Terlarut } \\
\left({ }^{\text {BBrix }}\right)\end{array}$ & $\begin{array}{c}\text { Klorofil } \\
(\mathrm{mg} / \mathrm{g})\end{array}$ & $\begin{array}{c}\text { Vitamin C } \\
(\mathrm{mg} / 100 \mathrm{gr})\end{array}$ \\
\hline $\mathrm{P}_{0}$ & 4,72 & 4,46 & 177,47 \\
$\mathrm{P}_{1}$ & 4,54 & 4,21 & 110 \\
$\mathrm{P}_{2}$ & 6,31 & 4,42 & 155,47 \\
$\mathrm{P}_{3}$ & 4,94 & 4,54 & 190,67 \\
\hline BNJ 5\% & TN & TN & \\
\hline Keterangan: TN & : Tidak Nyata & & \\
BNJ : Beda Nyata Jujur 5\% & &
\end{tabular}

Tabel 2. Menunjukkan bahwa pupuk kandang kambing $\left(\mathrm{P}_{2}\right)$ menghasilkan nilai tertinggi pada variabel total padatan terlarut yaitu 6,31 ${ }^{\circ}$ brix sedangkan pada variabel klorofil perlakuan pupuk kandang sapi $\left(P_{3}\right)$ menghasilkan nilai tertinggi yaitu 4,54 mg/g yang tidak berbeda jauh dengan perlakuan tanpa pupuk kandang $\left(P_{0}\right) 4,46 \mathrm{mg} / \mathrm{g}$ dan pupuk kandang kambing $\left(\mathrm{P}_{2}\right) 4,42 \mathrm{mg} / \mathrm{g}$. Pada variabel vitamin $\mathrm{C}$ perlakuan pupuk sapi $\left(P_{3}\right)$ menghasilkan nilai tertinggi yaitu $190,67 \mathrm{mg} / 100 \mathrm{gr}$.

Tabel 3. Rata-rata variabel pertumbuhan pada perlakuan kosentrasi boron.

\begin{tabular}{cccccc}
\hline \multirow{2}{*}{ Perlakuan } & \multicolumn{5}{c}{ Rata-rata Variabel Pertumbuhan } \\
\cline { 2 - 6 } & $\begin{array}{c}\text { Tinggi } \\
\text { Tanaman } \\
(\mathrm{cm})\end{array}$ & $\begin{array}{c}\text { Jumlah } \\
\text { Cabang }\end{array}$ & $\begin{array}{c}\text { Jumlah Daun } \\
\text { (helai) }\end{array}$ & $\begin{array}{c}\text { Luas Daun } \\
\left(\mathrm{cm}^{2}\right)\end{array}$ & $\begin{array}{c}\text { Bobot } \\
\text { Segar Daun } \\
\text { Kosumsi (g) }\end{array}$ \\
\hline $\mathrm{B}_{0}$ & 37,60 & 11,06 & 52,67 & 1243,17 & 7,38 \\
$\mathrm{~B}_{1}$ & 37,46 & 10,47 & 56,00 & 1423,59 & 8,40 \\
$\mathrm{~B}_{2}$ & 33,33 & 10,08 & 51,91 & 1248,73 & 8,73 \\
$\mathrm{~B}_{3}$ & 36,61 & 11,42 & 53,75 & 1505,97 & 8,61 \\
\hline BNJ 5\% & TN & TN & TN & TN & TN \\
\hline Keterangan: TN & : Tidak Nyata & & & & \\
& BNJ : Beda Nyata Jujur 5\% & & &
\end{tabular}


Tabel 4. Rata-rata variabel kualitas tanaman pada perlakuan kosentrasi boron

\begin{tabular}{cccc}
\hline & \multicolumn{3}{c}{ Rata-rata Variabel Kualitas } \\
\cline { 2 - 4 } Perlakuan & $\begin{array}{c}\text { Analisis Total } \\
\text { Padatan Terlarut } \\
\text { ('Brix) }\end{array}$ & $\begin{array}{c}\text { Analisis Klorofil } \\
\text { (mg/g) }\end{array}$ & $\begin{array}{c}\text { Analisis Vitamin C } \\
(\mathrm{mg} / 100 \mathrm{gr})\end{array}$ \\
\hline $\mathrm{B}_{0}$ & 4,29 & 5,41 & 196,53 \\
$\mathrm{~B}_{1}$ & 4,29 & 5,53 & 145,20 \\
$\mathrm{~B}_{2}$ & 4,54 & 5,74 & 155,47 \\
B $_{3}$ & 4,50 & 3,83 & 136,40 \\
BNJ 5\% & TN & TN & TN \\
\hline
\end{tabular}

Keterangan: TN : Tidak Nyata

BNJ : Beda Nyata Jujur 5\%

Tabel 3 dan 4. menunjukkan bahwa perlakuan pemberian boron tidak berpengaruh nyata peningkatan kualitas tanaman junggulan. Hal ini disebabkan karena faktor cuaca dengan curah hujan yang sangat tinggi pada saat proses penelitian.Hermawan (2009), menyatakan pengunaan boron untuk meningkatkan kualitas dan kandungan minyak kacang tanah masih belum memberikan hasil yang signifikan, hasil tersebut sama seperti hasil yang diproleh dari kandungan minyak, vitamin $\mathrm{C}$ dan klorofil dimana boron belum dapat menunjang peran dalam meningkatkan kualitas dan pertumbuhan kacang tanah. Kurang nyatanya pengaruh boron terhadap kualitas dan kandungan minyak kacang disebabkan oleh minimnya nutrisi pendukung pertumbuhan seperti nitrogen. Boron mampu meningkatkan tingkat penyerapan hara oleh tanaman (Mattas, 2009), namun ketika ketersediaan nutris juga minim maka kemungkinan yang menjadi penyebab mengapa kualitas dan kandungan minyak kacang tidak di pengaruhi secara nyata oleh aplikasi Boron.

\section{Kesimpulan dan Saran}

Perlakuan pemberian jenis pupuk kambing menunjukkan pengruh terhadap pertumbuhan jumlah cabang 8.11 luas daun yaitu $1810,08 \mathrm{~cm}$, dan rata-rata bobot kering berangkas tanman hasil terbaik yaitu 9,57 g untuk pupuk kandang sapi (P3) dan 6,27 g untuk pupuk kandang kambing (P2). Perlakuan Boron tidak pengaruh nyata terhadap kualitas tanaman junggul yaitu pada kadar klorofil, Vitamin $\mathrm{C}$ dan Total padatan terlarut).

\section{Daftar Pustaka}

Adimihardja, A., I. Juarsah, U. Kurnia. 2000. Pengaruh penggunaan berbagai jenis dan takaran pupuk kandang terhadap produktivitas tanah Ultisols terdegradasi di Desa Batin, Jambi. Pusat Penelitian Tanah dan Agroklimat, Bogor.

Baherta, S., dan R. M. Napitupulu. 2010. Kitab Tumbuhan Obat. Jakarta: Agriflo (Swadaya Grup). hlm. 21-22. 
BMKG. 2015. Data Suhu dan Curah Hujan Kota Malang. http://www.malang.jatim.bmkg.go.id/data-suhu-curah-hujan. Diakses 1 Januari 2019.

Hermawan, 2014. Penggunaan boron untuk meningkatkan pertumbuhan, hasil, dan kandungan minyak kacang tanah. Agrosains 16(2): 29-32.

Mattas M. A., A. Gonzales-Fontes, J. J. C. Camacho. 2009. Effect of boron supply on nitrate concentration and its reduction in roots and leaves of tobacco plants. Biologia Plantarum 53 (1): 120-124.

Seadh. 2009. Pertumbuhan dan kualitas anthurium hookeri pada berbagai pemberian boron. Sains Tanah-Journal of Soil Science and Agroclimatology, 5(2), 35-38. 